https://doi.org/10.3126/pragya.v8i01.42431

\title{
Financial Performance of Public Enterprises of Nepal
}

\author{
Dr. Rohit Kumar Shrestha* \\ Shiva Prasad Pokharel*
}

\begin{abstract}
Public enterprises are established, owned, and managed by the government to run industrial and commercial activities. The objective of the study is to examine the financial status of Public Enterprises (PEs) of Nepal. The study assesses based on some selected profitability indicators for eleven years. One public enterprise from each sector of the total of six sectors of them was selected. Secondary data was used. The sources such as the annual reviews by the Ministry of Finance, the annual report by Nepal Rastra Bank were chosen. This is purely quantitative research. Profitability ratios such as NPR, ROCE, ROE, and OER were employed over the years in analyzing the available financial information. Mean were computed for key analysis. NAC has the highest mean on NPR followed by NOC, DDC, JEMCL, and NEA. The NAC has the best financial status among sample PEs in terms of NPR.The finding suggests that the performance of NOC recorded the highest on ROCE. This is followed by NAC, NEA, JEMCL and DDC.NOC has the highest mean on ROE followed by RBB, NAC, JEMCL, DDC, and NEA. NEA has the highest mean on OER among the sample PEs. This is followed by DDC, NOC, NAC, RBB and JEMCL. NOC has the highest performance in terms of ROCE and ROE. Similarly, NAC has the highest performance on NPR. JEMCL seems to be the highest efficiency and cost-effective in terms of OER.
\end{abstract}

Keywords: financial indicators, financial performance, profitability, public enterprises

\section{Introduction}

Public sector enterprises (PSEs) are autonomous or semi-autonomous enterprises and companies established, owned, and managed by the government to run industrial and commercial activities. Public enterprises are established in both developed and developing countries of the world to enhance national development. Evidence points out that most of the public sector enterprises neither contribute remarkably to national development nor provide their public goods and service effectively and efficiently (Rishikesh, 2019). Public

\footnotetext{
* Dr. Shrestha is Associate Professor of Management, Padma Kanya Multiple Campus, TU, Nepal

*Mr. Pokharel is a PhD scholar and Associate Professor of Management, Patan Multiple Campus, TU, Nepal
} 
enterprises (PEs) were established and promoted after World War II for a welfare state through a planned development process. In Nepal, PEs have been established since the 1930s (Ministry of Finance, 2020) with some core objectives: to provide essential goods and services related to the daily life of all citizens at an affordable price, to ensure easy access of the goods and services to the citizens, to create employment opportunities, to lay the foundation of physical infrastructures for development, to develop self-reliant and independent economy, to assist in import substitution and export promotion, to establish welfare state, to create conducive environment to develop the private sector and on the whole to establish an egalitarian state to promote social justice. Biratnagar Jute Mill, as the first public enterprise in Nepal, was established in the year 1936.

The role of PEs in Nepal was dominant during the sixties and seventies with the main goal of economic development (Ghimire, n. d.). After the establishment of democracy in 1951, the Nepalese government prioritized establishing public sector enterprise with the objective of economic growth of the nation and of providing public essential goods and services to Nepalese people. At that time PEs were taken the same as the government department. PEs, however, couldn't run a business-like manner. They had becomea heavy burden to the poor national economy. To improve the performance of the PEs, the government adopted some reform processes in the early and mid-1990s. Despite various reform processes adopted by the government, PEs couldn't be improved and problems and issues were getting worse. Hence, the government started the privatization process formulating a privatization policy in 1992 and enacting the privatization Act, 1994. Nepalese Public Enterprises are classified under six sectors. As of today, there are a total of 44 PEs in existence:10 each PEs in Service and Industrial, 6 PEs in Trading, 5 each PEs in Social and Public Utility and 9 PEs are in the Financial sector (Ministry of Finance, 2020). Out of them, only 33 PEs are presently in operation.

Financial performance indicators show the various aspects and positions of the performance of the organizations. The study and concept of financial performance and research into its measurement are well established and advanced within fields of management and finance (Yeboah \& Mensha, 2014). They remark financial analysis is very important in institutional restructuring and estimating the impact of any sector reform. Ministry of Finance, (2018) reviews:

The amount of the net profit of Public Enterprises hasbeen increasing trend during the last few years. In the review period, Service, Public Utility, and Finance SectorPEs have earned net profit; however, Industrial and Social Sector PEs are having net loss in most ofthe years. The role of thePublic Utility Sector is crucial to the net profit in FY 2016/17. The reason is, Nepal Electricity Authority was having a net loss for a long period but now, it has earned 
net profitin this FY and the Nepal Doorsanchar Company Ltd has increased its net profit. In the review period, Trading and Financial Sector PEs hold the second and third position respectively amongthe profit-making PEs. The return on government investment as a dividend from PEs has been increasing during the reviewyears. Government should pay attention to strengthening PEs in Nepal. Efficient and sound PEs can contribute to many sectors such as employment generation, contribution to GDP and NDP, foreign exchange earnings, contribution to the government revenue, and profitability.

Statement of the problem

The overall analysis of PEs in Nepal indicates that they have been weakening the government fiscal position due to suffering from continuous financial losses, have a poor quality of service, and have become a huge burden to the government (Wagle et al., 2013).Nepalese public enterprises have been confronted with various problems like monuments of mismanagement, inefficiency, lack of adequate technology, frequent political interferences, poor responsibility, overstaffing, and lack of proper attention fromthe government. These problems adversely affect the financial performance of PEs. A large number of PSs have become economically unviable and chronically loss-making or sick. Ministry of Finance (2018) states weak management, fiscal inefficiency, decreasing commercial goals, and lack of clarity of structural and institutional aspects as problems and challenges in overall operation and management of PEs. These problems directly or indirectly affect the financial performance of PEs. So, the PEs have become a huge financial as well as administrative burden to the nation. The health of the financial position of Nepalese PEs is crucial to achieving its corporate vision, mission, and objectives. However, the overall profitability status of the PEs seems to be either negative or very poor. The following research questions have been set aiming to respond:

"What is the financial performance of Public Enterprises of Nepal?”

\section{The objective of the study}

The objective of the study is to examine the financial performance of the Public Enterprises of Nepal.

\section{Review of literature}

Sethy's (n. d.) studyon "Performance of Public Sector Enterprises in India" found performance in many sectors i.e. employment generation, contribution to NDP, contribution to Gross Domestic Capital Formation, Foreign Exchange Earnings, contribution to the government exchequer, and profitability. The profitability of public sector enterprises is not encouraging. Although some public enterprises are successful to earn a good amount of 
profit, a good number of other public enterprises are incurring a huge loss. However, in recent years the performance of Central Public Sector Enterprises (CPSEs) has been improving.

Chittedi \& Singh (2012) on "Performance of Public Sector Enterprises in India: A MacroLevel Analysis" concluded that PSEs performed better in the post-reform period compared to the pre-reform period. In the early years of establishment, the source of funds of these enterprises was budgetary support. And, the profitability of Central Public Sector Enterprises (PSEs) showed improvement and made themraise resources internally. Profitability is considered an important indicator of performance for every enterprise. Both retained profits, as well as dividends of CPSEs, have shown an upward movement and its rise is sharper in the post-reform period compared to the pre-reform period.

Ravinder \&Rupinder's (2007) study states that the empirical evidence supports the positive effects of privatization on PSEs' performance. These privatized units have significantly improved their efficiency including the level of profitability. Arun and Nixson (2000) argue that the major purpose of disinvestment has been to reducethe public sector borrowing requirement.

Jain \& Yadav (2005) analyzed the financial performance of the Public Sector Enterprises in terms of profitability by using secondary data. The findings showed that thesample PSEs have earned a satisfactory rate of return on the capital employed. The reason forthe better profitability of PSEs might be the liberalization policy measures taken by thegovernment.

Pokharel \& Pokhrel's study (2019) on "Impact of Liquidity on Profitability in Nepalese Commercial Bank" inferred that the profitability positions of the banks were fluctuating every year. The ratio of Agricultural Development Bank Limited had the highest on ROA and that of Everest Bank Limited hadthe highest ROE. The performance of privatized enterprises in Nepal was not seen as satisfactory.

The cumulative losses of these enterprises have been increasingly adding a burden on the treasury (Ghimire, n. d.). Maurya et al., (2015) stated profits earned by most of the State Level Public Enterprises (SLPEs) were very small. Seven out of sixteen major SLPEs could earn a good return on their capital. Similarly, poor fiscal management in terms of utilization of capital employed in the revenue generation was reflected from the low mean.

A high quantum of decline has been witnessed in the majority of the parameters of lossincurring public sector enterprises (PSEs) after disinvestment; their position has deteriorated over the years of the study. In contrast, the financial performance of profit-making PSEs has shown improvement in a majority of the parameters after disinvestment. The result suggests 
the better performance of profit-making PSEs compared to loss-incurring PSEs (Gupta et al., 2011).

The results suggest that the financial performance of State-owned Enterprises (SOEs) improves significantly when firms are corporatized. Therefore, the main difference in the financial performance is caused by the difference in the objectives of the firm, not the property or some dubious political activities (Bozec \& Breton (2003).

Discovered from the study results that government assistance and guarantee to state-owned enterprises in South Africa harmed their financial performance. if the government wants to enhance the performance of these underperforming SOEs that are in continued need of bailouts, the emphasis should be on some of these key variables (Marimuthu, 2020).

\section{Methodology}

This study used quantitative method. Secondary data was used in the study since all the information needed was historical in nature and available The sources such as the annual review by the Ministry of Finance, www.gov.np, annual report by Nepal Rastra Bank, www.nrb.org.np, journals, and websites were chosen when found relevant. Eleven years (2008/009 to 2018/019) of financial statements were selected from one each of the entire six sectors of PEs. Profitability ratios such as Net Profit Ratio (NPR), Return on Capital Employed (ROCE), Return on Equity (ROE), and Operating Expenses Ratio (OER) were computed over the years in analyzing the available financial status. Mean was computed for key analysis. Some of the data of the study period were not available. It has been indicated by N. A. in the concerned table. The study includes six public enterprises i. e. Nepal Oil Corporation (NOC) from trading sector, Dairy Development Corporation (DDC) from the industrial sector, Nepal Airlines Corporation (NAC) from the service sector, Janak Education Materials Center Limited (JEMCL) from the social sector, Nepal Electricity Authority (NEA) from public utility sector and Rastriya Banizya Bank Limited (RBBL) from the financial sector.

\section{Results and discussion}

Financial indicators are best in analyzing financial performance. Profitability is considered animportant financial indicator in analyzing financial performance for every enterprise. The profitability ratios are related to profit. The ratios are used as a measure to judge the operating efficiency of an organization (Wagle et al., 2068 BS). The ratios can also show the overall efficiency of the enterprise.

Table 1: Profitability ratios of NOC, DDC and NAC (Ratios in percent)

\begin{tabular}{|l|l|l|l|l|l|l|l|l|l|l|l|l|}
\hline \multirow{2}{*}{ year } & NOC & DDC & \multicolumn{4}{l|}{ NAC } \\
\cline { 2 - 10 } & NPR & ROCE & ROE & OER & NPR & ROCE & ROE & OER & NPR & ROCE & ROE & OER \\
\hline
\end{tabular}


Patan Pragya (Volume: 8, Number: 1 2021)

ISSN No. 2595-3278

\begin{tabular}{|l|l|l|l|l|l|l|l|l|l|l|l|l|}
\hline $2008 / 009$ & 7 & 142 & 3427 & 93 & 0.39 & 2.64 & 2.64 & 101.1 & 0.57 & 0.89 & 18.48 & 99.11 \\
\hline $2009 / 010$ & -1.46 & -30.88 & -869 & 102 & 0.98 & 7.80 & 7.46 & 99.43 & N.A. & N.A. & N.A. & N.A. \\
\hline $2010 / 011$ & -7 & -81 & -5282 & 107 & 2.9 & 22.21 & 20.96 & 97.45 & 0.35 & 4.93 & 11.51 & 97.4 \\
& & & & & & & & & & & & \\
\hline $2011 / 012$ & -9 & -52 & 8152 & 111 & -5.08 & -89.13 & -69.43 & 106.2 & -0.34 & -5.42 & -12.35 & 98 \\
\hline $2012 / 013$ & -2 & 136 & -2124 & 102 & 2.45 & 30.47 & 28.32 & 98.69 & 4.54 & 5.24 & 21.42 & 94.76 \\
& & & & & & & & & & & & \\
\hline $2013 / 014$ & -3.21 & -4.19 & -8584 & 103 & -3.91 & -80.51 & -72.33 & 106 & 0.8 & 4.01 & 2.48 & 98.96 \\
\hline $2014 / 015$ & -11 & 0.81 & 1555 & 84 & 1.2 & 22.77 & 20.37 & 100.3 & 2.71 & 6.09 & 6.89 & 96.38 \\
\hline $2015 / 016$ & 19.89 & 3.47 & 3.72 & 75 & 3.67 & 44.24 & 40.51 & 97.98 & 0.47 & 9.19 & 1.40 & 99.37 \\
\hline 2016/017 & 7 & 46 & 93 & 90 & -5.2 & -146.8 & -118.6 & 106.6 & 1.65 & 4.31 & 5.36 & 90.58 \\
\hline $2017 / 018$ & 2 & 13 & 24 & 98 & 1.49 & 31.03 & 26.24 & 100.6 & 1.87 & 3.13 & 6.5 & 85.5 \\
\hline 2018/019 & 5 & 32 & 51 & 96 & 0.49 & 1.84 & 7.61 & 100.7 & & 3.98 & & 79.11 \\
\hline Total & 7.22 & 205 & 1044 & 1061 & -0.62 & -153.44 & -106.3 & 1115 & 12.62 & 36.44 & 61.69 & 939.17 \\
\hline Mean & 0.66 & 18.64 & 949.7 & 96.45 & -0.06 & -13.95 & -9.64 & 101 & 1.15 & 3.64 & 6.85 & 93.92 \\
\hline S. D. & 8.45 & 66.33 & 6458 & 10 & 3.03 & 49.93 & 49.73 & 3.21 & 1.41 & 3.63 & 9.36 & 6.47 \\
\hline C. V. & 1280 & 355.8 & 680 & 10.4 & -489 & -358 & -516 & 3.18 & 123 & 99.73 & 136.6 & 6.89 \\
\hline
\end{tabular}

Table 2: Profitability ratios of JEMCL, NEA and RBBL (Continued from table 1) (Ratios in percent)

\begin{tabular}{|c|c|c|c|c|c|c|c|c|c|c|c|c|}
\hline \multirow[t]{2}{*}{ year } & \multicolumn{4}{|c|}{ JEMCL } & \multicolumn{4}{|l|}{ NEA } & \multicolumn{4}{|c|}{ RBBL } \\
\hline & NPR & ROCE & ROE & OER & NPR & ROCE & ROE & OER & NPR & $\begin{array}{l}\text { ROC } \\
\text { E }\end{array}$ & ROE & OER \\
\hline 2008/009 & -25.4 & -24.7 & -47.8 & 125.4 & -38.4 & -7.45 & -28.6 & 149.4 & & & 176 & 78 \\
\hline $2009 / 010$ & -15 & -13 & -20 & 115 & -23.6 & -5.1 & -18.6 & 130.4 & & & 163 & 74 \\
\hline $2010 / 011$ & -16.3 & -14.1 & -21 & 116.3 & -33.9 & -6.77 & -22.3 & 141.6 & & & 150.1 & 81 \\
\hline 2011/012 & N. A. & N. A. & N.A. & N.A. & -49.5 & -10.7 & -41.5 & 158 & & & 21.54 & 99.6 \\
\hline $2012 / 013$ & N. A. & N.A. & 25 & N.A. & $\begin{array}{l}-18.3 \\
\end{array}$ & -4.67 & -18.8 & 128.1 & & & 103 & 91.5 \\
\hline $2013 / 014$ & N. A & N. A. & N.A. & N.A. & -17 & -5 & -17 & 125 & & & 77 & 87.3 \\
\hline $2014 / 015$ & -7 & N.A. & N.A. & 86 & -16 & -5 & -18 & 129 & & & 69.6 & 71.6 \\
\hline $2015 / 016$ & -23 & N.A. & -40 & N.A. & -28 & -8.0 & -36 & 138 & 0.58 & 0.04 & 27.4 & 79.5 \\
\hline $2016 / 017$ & -34.4 & -74.8 & 62.6 & 132.3 & 3 & 1 & 3 & 107 & & & 26 & 70 \\
\hline $2017 / 018$ & 10 & 7 & -9 & 78 & 6 & 2 & 4 & 106 & & & 30.5 & 37 \\
\hline $2018 / 019$ & 1.96 & 0.26 & 0.48 & 64.03 & 15 & 3 & 8 & 100 & & & 23.4 & 58.9 \\
\hline Total & -109.1 & -119 & -49.7 & 717 & -201 & -46.7 & -186 & 1413 & & & 867.4 & 828.4 \\
\hline Mean & -13.6 & -19.9 & -6.22 & 102.4 & -18.3 & -4.24 & -16.9 & 128.4 & & & 78.87 & 75.31 \\
\hline S. D. & 13.75 & 26.32 & 33.62 & 24.29 & 18.82 & 4.19 & 15.33 & 17.46 & & & 57.53 & 16.05 \\
\hline C. V. & -101 & -132 & -541 & 23.72 & -103 & $\begin{array}{l}-98.8 \\
\end{array}$ & -90.7 & 13.6 & & & 72.94 & 21.31 \\
\hline
\end{tabular}


Tables 1 and 2 expresses that the sample PEs' financial performance is in a muchfluctuating trend throughout the studied period. The relationship between net profit/loss and sales revenue is measured through the Net Profit Ratio (NPR) or Net Profit Margin. To ascertain this ratio, the net profit or loss is divided by sales revenue. A higher ratio indicates the higher overall efficiency of the enterprises and better utilization of resources. A higher margin indicates the capacity of an organization to manage successfully. The above tables show that NAC and NOC recorded positive NPR under review and vice versa by other PEs. NAC has the highest mean on NPR i. e. 1.15, followed by NOCi. e. 0.66 , DDCi. e. -0.06, JEMCL i.e. -9.91 and NEAi. e. -18.3. NPR of NAC shows positive except FY 2011/012 in the study period.

The NAC has the best financial status among sample PEs in terms of NPR. NPR of NAC recorded the highest in 2012/013 at 4.54 whiles the lowest of -0.34 was registered in 2011/012. Although NOC's past performance looks poor, it has been earning profit from FY 2015/016 to FY 2018/019 continuously. Overall NPR status is the worst and poorest in NEA. NEA had incurred a greater loss before FY 2015/016. Its profitability status is encouraging since FY 2016/017 to the studied period. JEMCL also incurs losses except FY 2017/018 and 2018/019. RBB lacks information on both NPR and ROCE throughout the studied period. Hence, NAC and NOC have good financial performance and efficiency in terms of NPR.

Others are the poor performer and low efficient or inefficient in this respect. In terms of NPR, SD of NOC, DDC, NAC, JEMCL and NEA are 8.45, 3.03, 1.41, 13.75, and 18.82 respectively. NAC has the lowest value of SD on NPR that indicates more close to the mean. It means that NAC has relatively more consistent NPRi. e. 1.41 percent. NEA has the highest SD on NPR. It means NEA's NPR is relatively more heterogeneous. Similarly, CV of NAC, DDC, NOC, JEMCL and NEA in terms of NPR are 1280, -489, 123, 101 and -103 respectively. By measuring $\mathrm{CV}, \mathrm{NAC}$ is applying relatively more positive consistent NPR since it has a lower CV of 123 percent than NOC i.e. 1280 percent that is more variable. NPR of DDC, JEMCL and NEA is negative with 489, 101 and 103.

Return on Capital Employed (ROCE) presents the relationship between net profit after tax and capital employed. A higher ratio indicates the better utilization of capital employed. Return on Capital Employed (ROCE) on the other hand has also fluctuated during the last eleven years (from 2008/009 to 2018/019). The finding suggests that the performance of NOC recorded the highest of 18.64 on ROCE. This is followed by NAC with 3.31, NEA with -4.25, JEMCL with -10.8, and DDC with -13.95. ROCE of NOC is in increasing trend from $2014 / 015$ to $2018 / 019$. Before $2014 / 015$ it is in a negative 
position except FY 2008/009. ROCE of NOC had recorded the lowest in 2009/010 at 30.38 whilst the highest of 142 was recorded in 2008/009. NEA has improved ROCE with a positive figure since 2016/017, but before date i. e. from 2008/009 to 2015/016 it was very poor status. ROCE implies that NOC hasa better return on permanent capital employed. This indicates the high efficiency of the enterprise on the utilization of total capital. NAC also has a good return on permanent capital employed. Other enterprises seem to have poor performance and inefficiency. DDC has the worst and poorest in terms of ROCE. In terms of ROCE, SD of NOC, DDC, NAC, JEMCL, and NEA are 66.33, 49.93, 3.63, 26.32 and 4.19. Similarly, the CV of ROCE of the enterprises is 355.8, -358, 99.73, -132 and -98.8 respectively. By computing SD and CV, NAC hasa relatively more homogenous and positive ROCE since it has a lower SD of 3.63 percent and CV of 99.73 percent. NEA's ROCE hasthe second-lowest SD.

Return on Equity (ROE) expresses the relation between the net profit after tax and the shareholder's fund. This ratio is a measure of the profitability of a business that indicates how well the business has used the resources contributed by the owners. During the period under review, NOC has the highest mean on ROE i.e. 949.7 followed by RBBi. e. 78.9, NAC i. e. 5.61, JEMCLi. e. -4.52, DDCi. e. -9.64 and NEA i. e. -16.9. ROE of NOC had recorded the lowest in 2013/014 at -8584 whilst the highest of 15555 was recorded in 2014/015. DDC seems to be effortful to improve its ROE. Despite huge inefficiency and very poor performance on ROE, NEA has been improving its ROE in later studied periodsi. e. from 2016/017. Lately, DDC is also in an optimistic position. JEMCL has the poorest and very inefficient situation in this regard.In terms of ROE, SD of NOC, DDC, NAC, JEMCL, NEA and RBBL are 6548, 49.73, 9.36, 33.62, 15.33 and 57.53 respectively. NAC has ranked 1 st. This is followed by NEA, JEMCL, DDC, RBBL and NOC respectively. ROE's CV of the enterprises is $680,-5.16,136.6,-541,-90.7$ and 72.94 respectively.

Operating expenses include the cost of goods sold, administrative expenses, and selling and distribution expenses. The higher ratio shows the increase in operating expenses and decrease in a business capacity and lower the operating ratio indicates the higher operating profit (Dangal, 2067 B. S.) NEA has the highest mean on OERi. e. 128 among the sample PEs. This is followed by DDC i.e. 101, NOC i.e. 96.45, NAC i.e. 85.4, RBBL i. e. 75.3 and JEMCL i.e. 65.2.0ER of NEA recorded the highest in 2011/012 at 158 while the lowest of 100 was registered in 2018/019 when net profit just recovered operating expenses. The highest cost incurred by NEA indicates the worse performance and higher inefficiency of the management from the angle of cost. Despite the worse performance and efficiency, the OER of NEA is in decreasing trend during later studied period i. e. from $2016 / 017$ to $2018 / 019$. 
The OER of DDC also indicates worse performance and efficiency due to higher operating expenses than sales revenue. This ratio of NEA and NAC is in a declining trend since 2014/015 to studied period. RBBL and JEMCL show relatively low OER. However, in recent years (2016/017 to 2018/019) the financial status in terms of NPR, ROCE, ROE, and OER of NEA has been improving. OER's SD of NOC, DDC, NAC, JEMCL, NEA and RBBL have 10, 3.21, 6.47, 24.29, 17.46, and 16.05 respectively. DDC is relatively more consistent since it has lower SD i. e. 3.21. This is followed by NAC, NOC, RBBL, NEA, and JEMCL. Likewise, CV of NOC, DDC, NAC, JEMCL, NEA, and RBBL have 10.4, 3.18, 6.89, 23.72, 13.6, and 21.31. DDC has also the lowest CV in terms of OER. This is followed by NAC, NOC, NEA, RBBL, and JEMCL which have the most variable in terms of both SD and CV.

The study discovers that NAC has the highest mean on NPR. Overall NPR status is the worst and poorest in NEA. NEA had incurred a greater loss before FY 2015/016. Its profitability status is encouraging since FY 2016/017 to the studied period. NOC recorded the highest mean on ROCE and ROE. It has also the second-highest NPR. So, NOC has the highest financial position. This is followed by NAC. DDC has the worst and poorest in terms of ROCE. Lately, DDC is also in an optimistic position. JEMCL has the poorest and very inefficient situation on ROCE. NEA has the highest mean on OER. The highest cost incurred by NEA indicates the worse performance and higher inefficiency of the management from the angle of cost. Despite the worse performance and efficiency, the OER of NEA is in decreasing trend during later studied period i. e. from $2016 / 017$ to $2018 / 019$.

The overall financial performance of Nepalese PEs is poor. Despite it, NOC and NEA have been unexpectedly and surprisingly improving from FY 2015/016 to 2018/019 and from 2016/017 to 2018/019 respectively compared to previous years within the studied period. The performance of RBBL in terms of ROE and OER has been positive throughout the studied period. Likewise, the financial performance of NOC has been positive throughout the studied period except FY 2011/012. DDC seems to have mixed and poor status. The overall financial performance of JEMCL has been negative and unsatisfactory. By measuring SD and CV, NAC is applying relatively the most consistent NPR, ROCE, and ROE since it has the lowest SD and CV in the context of the variables. SD of NPR of NEA is comparatively more variable.NEA hasthesecond-lowest SD in terms of ROCE and ROE. DDC has relatively lower SD and CV in terms of OER. NAC holds a second-lowest position in respect of OER.This finding is in line with the studies of Maurya et al., (2015), Singh \& Singh (2015) and Pokharel \& Pokhrel (2019).

\section{Conclusions}

The financial performance of PEs has been analyzed based on profitability ratios, namely, NPR, ROCE, ROE, and OER. These are areas that the analysis focused on profitability is considered asimportant and the best financial indicator in analyzing financial performance for every enterprise. Despite the poor overall profitability of PEs, NAC has the highest mean on NPR. This is followed by NOC, DDC, JEMCL, and NEA. The NAC has the best financial status and the highest efficiency to utilize resources among sample PEs. So, NAC 
ranked $1^{\text {st }}$ in terms of NPR. Similarly, NOC ranked $2^{\text {nd }}$ with a positive figure. DDC, JMCL, and NEA ranked $3^{\text {rd }}, 4^{\text {th }}$, and $5^{\text {th }}$ respectively. ROCE on the other hand has also fluctuated during the last eleven years. NOC recorded the highest mean on ROCE. This is followed by NAC, NEA, JEMCL, and DDC. NOC ranked $1^{\text {st }}$ in terms of ROCE. So, NOC has the highest capacity to utilize permanent capital. NOC has also the highest mean on ROE, followed by RBBL, NAC, JEMCL, DDC, and NEA.NOC ranked $1^{\text {st }}$ concerning ROE. RBB and NAC ranked $2^{\text {nd }}$ and $3^{\text {rd }}$ with the plus situation. So, they have been successful at efficient management and utilization and maximization of shareholders' funds or wealth. JEMCL, DDC, and NEA ranked $4^{\text {th }}, 5^{\text {th }}$, and $6^{\text {th }}$ with a negative figure. NEA is the worst performer and highest inefficient in terms of ROE. NEA has the highest mean on OER among the sample PEs. This is followed by DDC, NOC, NAC, RBBL, and JEMCL. The highest cost incurred by NEA indicates the worse performance and higher inefficiency of the management from the angle of cost. However, the findings suggest that in recent years the financial status of NOC and NEA has been improving. By measuring SD and CV, NAC is applying relatively the most homogeneous NPR, ROCE, and ROE since it has the lowest SD and CV in the context of the variables. SD of NPR of NEA is comparatively more inconsistent. NEA has the second-lowest SD in terms of ROCE and ROE. DDC has relatively lower SD and CV in terms of OER. NAC holds a second-lowest position in respect of OER. Considering the overall financial status researcher here finds Nepal Oil Corporation to be the best and Janakpur Education Material Center Limited to be the worst.

\section{References}

Agrawal R. C. (n. d.). Public Enterprises: Definitions and Characteristics of Public Enterprises. Arun T. G. and Nixson F. I. (2000). Disinvestment of Public Sector Enterprises: The Indian Experience. Oxford Development Studies, 28 (1), 19-32

Arun T. G. and Nixson F. I. (2000). Disinvestment of Public Sector Enterprises: The Indian Experience. Oxford Development Studies, 28 (1), 19-32. Retrieved from https://www.yourarticlelibrary.com/enterprise

Bozec R. and Breton G. (2003). The impact of the corporatization process on the financial performance of Canadian state-owned enterprises. International Journal of Public Sector Management, https://www.emerald.com/insight /content/doi/10.1108/09513550310456409/full /html?fullSc=1\&mbSc=1

Chittedi K. R. and Singh J. (2012). Performance of Public Sector Enterprises in India: A MacroLevel Analysis. The IUP journal of managerial economics, ix (3), 7-25. Retrieved from https://www.researchgate.net/publication/255726283 _Performance_of_Public_Sector_Enterprises_in_India_A_MacroLevel_Analysis/link/54e314950cf2d

Dangal R. M. (2067 B. S.). Accounting for financial analysis and planning. TalejuPrakashan, Kathmandu.

Ghimire R. (n. d.). Privatization of public enterprises in Nepal. Retrieved from https://www.academia.edu/38886263/privatization

Gilbert S.Y. and Charles M. (2014). A critical analysis of financial performance of agricultural development bank (adb, ghana), European journal of accounting auditing and finance research, 2(1), 1-23.https://eajournals.org/wp-content/uploads/A... 
Gupta S., Jain_P.K. and_Yadav S. S. (2011). Impact of MoU on financial performance of public sector enterprises in India. Journal of advance in management research.

Jain P. K. and Yadav S. S. (2005). Financial Management of Public Sector Enterprises in India, Analysis of Profitability. Economic and Political Weekly.

Maican O. H. (2013). Legal status of public enterprises and commercial monopolies. Juridical tribune, 3 (1). Retrieved from htts://www.researchgate.nt/publication /227489931

Marimuthu F. (2020). Government assistance to state-owned enterprises: a hindrance to financial performance. Investment management and financial innovations, 17 (2), 40-50. retrieved from https://www.researchgate.net/publication/ 341410997

Maurya N. K.., Singh S. and Singh A. K. (2015). Financial performance of state level public enterprises in Uttar Pradesh. The journal of institute of public enterprises, 38(3\&4), 84103.

Ministry of Industry, Commerce and Supplies (2018). Nepal trade policy review-2018. .Retrieved from https://moics.gov.np/uploads/shares/policy/Trade\% 20Policy\%20Review\%202018-

Ministry of finance (2010 to 2020). Annual performance review of public enterprises. Ministry of finance, Kathmandu, Nepal.

National Planning Commission. (2018). The fourteenth plan fiscal year. National Planning Commission- Kathmandu.

Nepal Rastra Bank. (2017). Annual report. Nepal Rastra Bank-Kathmandu.

Nepal Rastra Bank. (2020). Annual report (Fiscal year 2019/20). Nepal Rastra Bank-Kathmandu.

Pokharel S. P. and Pokhrel B. P. (20). Impact of liquidity on profitability in Nepalese commercial bank. Patanpragya, 5(1), 180-187.

Ravinder V. and Rupinder (2007). The Effects of Disinvestment on Financial and Operational Performance of Public Sector Enterprises: Some Reflections. The Journal of Institution of Public Enterprise, 30 (1 \& 2).

Rishikesh P. (2019). Performance of public enterprises and its management challenges in Nepal. South asian journal of marketing and management research, 9(4), 8-34.

Gupta S., Jain P. K., Yadav S. S and Gupta V. K. (2010). Financial performance of disinvested central public sector enterprises in India: An empirical study on select dimensions. Journal of Applied Finance \& Banking, 1, (4), 57-106. Retrieved from https://www.scienpress.com/Upload/JAFB/Vol\%201_4_3.pdf

Sethy B. (n. d.). Performance of Public Sector Enterprises in India.

Wagle B., Acharya K. and Sapkota S. (2013). Analysis of the performance of public enterprises. Samriddhi, the prosperity foundation. Kathmandu.

Wagle K. N. (2068 BS). Accounting for financial analysis and planning. Khanal publication Pvt. Ltd, Kathmandu. 